\title{
GREEN AND SIMPLE UV-VISIBLE DIFFUSE REFLECTANCE AND TRANSMITTANCE METHODS FOR THE DETERMINATION OF NITROFURANTOIN IN PHARMACEUTICAL PREPARATIONS
}

\author{
M. Tubino ${ }^{1 *}$, L. F. Bianchessi ${ }^{1}$, M. Palumbo ${ }^{1}$ and M. M.D.C. Vila ${ }^{2}$ \\ 'Institute of Chemistry, State University of Campinas, CP 6154, CEP 13083-970, Campinas, SP, Brazil \\ ${ }^{2}$ University of Sorocaba, Pharmacy Course, Sorocaba, SP, Brazil \\ *tubino@iqm.unicamp.br
}

Two quantitative analytical methods for the determination of nitrofurantoin in pharmaceutical preparations in the visible-ultraviolet range of the spectrum are reported. One of them uses the diffuse reflectance technique and the other transmittance measurements in aqueous solution. Both procedures are very simple to be performed and also present green characteristics as only polyethylene glycol and water are used as solvents. Commercial pharmaceutical preparations of the drug were analyzed using the proposed methods. The results were compared with those obtained when the HPLC procedure recommended by the USP was applied. Statistical comparison using the paired Student's t test and the Snedecor's F test showed good agreement between all the methods.

Keywords: nitrofurantoin ; UV-visible diffuse reflectance ; transmittance, pharmaceutical preparations

\section{Introduction}

Nitrofurantoin, [N-(5-nitro-2-furyldine)-1-aminohydantoin], $\mathrm{C}_{8} \mathrm{H}_{6} \mathrm{~N}_{4} \mathrm{O}_{5}$, whose structural formula is shown in Figure 1, is a nitro compound very active against gram-positive and gram-negative bacteria [1]. It is also effective against Proteus and Pseudomonas aeruginosa, particularly in the acidic medium of the urinary treat. This drug is used as antibacterial agent in urinary infections with doses from 5 to $10 \mathrm{mg}$ per day[2,3].

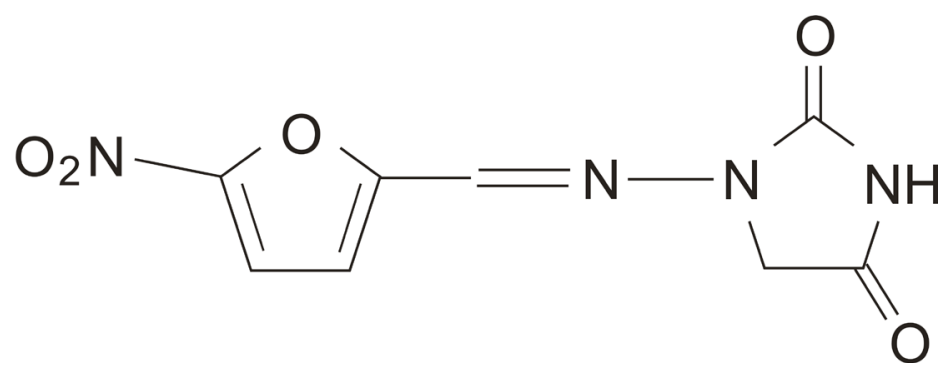

Figure 1. Structural formula of nitrofurantoin [1]

The mechanism of action of the 5-nitrofuranic derivatives is not yet completely elucidated $[4,5]$. Nitro- furantoin is absorbed after oral intake, however it does not reach therapeutic concentrations in the plasma and in the tissues since it is rapidly eliminated through both renal and biliary routes after rapid absorption in the gastro-intestinal tract. ${ }^{2}$ Since macrocrystalline nitrofurantoin is more slowly absorbed and presents less collateral effects, it is usually commercialized in this form $[2,6]$.

Some analytical methods are employed for the determination of nitrofurantoin in pharmaceutical preparations. For example: spectrophotometric [7-10]; spectrofluorimetric $[11,12]$; voltametric $[13,14]$; chromatographic $[15,16]$, methods have been described.

The development of simple and rapid analytical methods is always interesting. Diffuse reflectance spectroscopy in the ultraviolet and visible region of the spectrum frequently allows the direct quantitative analysis of analytes with a minimum of treatment, with consequent decreases in manipulation and in the use of organic solvents and chemical reagents. The diffuse reflectance spectroscopy using spot tests has been used with success in quantitative analysis of many drugs [1719, 21-24].

In aim of the present work was the development of a quantitative diffuse reflectance method, in the ultraviolet-visible range of the spectrum, for the deter- 
mination of nitrofurantoin in the bulk drug and in pharmaceutical preparations. A priori the intention was to obtain a procedure with two fundamental characteristics, i.e., it must be green and it must be easy to perform.

\section{Experimental}

\section{Chemicals}

All the reagents and solvents used were of analytical grade. Polyethylene glycol (40 k) and bidistilled water were used as solvents.

\section{Reflectance support}

For the reflectance measurements waxed paper was used as support for the analyte solution in polyethylene glycol.

\section{Apparatus}

HPLC: Shimadzu Prominence with SPPM20A diode array; column (Waters) - m-Bonbapak C18 (300 mm ' 3.9 mm I.D.), particle size, $10 \mathrm{~mm}$; pore size, 125 angstrons; injection volume, $20 \mathrm{~mm}$.

Spectrophotometer: Shimadzu UV-2450 ultraviolet visible spectrophotometer equipped with a reflectance accessory.

Lab-made reflectometer: The home made reflectometer has already been described in detail [20]. In the present case a blue E1L31-3G0A2 Toyoda Gosei Co. Ltd. LED was used: $Æ 3 \mathrm{~mm}$ E.D.; view angle 15 degrees.

Analytical balance: Mettler Toledo AX-205, $0.1 / 0.01 \mathrm{mg}$.

\section{Procedures}

Diffuse reflectance method using Shimadzu 2405 device or the lab-made reflectometer

Analytical curve

The analytical curve was constructed by preparing solutions of nitrofurantoin in $40 \mathrm{k}$ polyethylene glycol. In order to adequately dissolve the analyte these solutions were heated to $60{ }^{\circ} \mathrm{C}$, a temperature where the solvent is liquid, allowing perfect homogeneization.

The analytical grade nitrofurantoin used to construct the calibration curve was initially mixed with the excipients starch, talc and lactose $(1: 1: 1 \mathrm{w} / \mathrm{w})$ in order to obtain a content of about $274 \mathrm{mg} \mathrm{g}^{-1}$, which is the nominal concentration of the analyte in the pharmaceutical preparation.

Exact masses of that mixture, weighed to 0.1 $\mathrm{mg}$, from ca. $0.015 \mathrm{~g}$ to ca. $0.045 \mathrm{~g}$, were dissolved in ca. $3.0 \mathrm{~g}$ of polyethylene glycol, also weighed to 0.1 $\mathrm{mg}$. The analytical curve from ca. $1.4 \mathrm{mg} \mathrm{g}^{-1}$ to ca. 4.0 $\mathrm{mg} \mathrm{g}^{-1}$ of nitrofurantoin in polyethylene glycol was constructed in this way.

The spectra were registered from $300 \mathrm{~nm}$ to 500 $\mathrm{nm}$ but the absorbance values at the maximum absorptivity $(385 \mathrm{~nm})$ were considered for analytical purposes.

The nitrofurantoin solutions were put on the support (waxed paper) without the necessity of weighing this aliquot: a quantity was placed on a folded paper (Fig. 2A). The two parts were closed, followed by heating for 5 minutes at $60{ }^{\circ} \mathrm{C}$ in an oven. In sequence the paper was opened, the excess of the "ointment" was removed manually with absorbent paper, for example, a paper handkerchief. In this part of the procedure, the insoluble excipients are all mechanically removed leaving the sample clean. A foil of black PVC (polyvinylchloride) was put between the two parts of the paper (Fig. 2B) and the absorbance of the diffuse reflectance process was determined at $385 \mathrm{~nm}$ in the Shimadzu spectrophotometer or in the portable device constructed in our laboratory using a blue light emitter diode [20]. In the manual reflectometer the measurements are made by placing it on the paper containing the analyte. For the blank, paper imbedded with the polyethylene glycol was used.

\section{Treatment of the samples}

The content of 20 capsules of the pharmaceutical preparation was carefully crushed in a mortar. A quantity of this powder large enough to obtain a concentration of ca. $3.5 \mathrm{mg} \mathrm{g}^{-1}$ in polyethylene glycol was weighed. The procedure followed was the same described above for the analytical curve.

Transmission method using the UV-VIS spectrophotometer

The solubility of the nitrofurantoin in water is very low. However in polyethylene glycol it is very high. Solutions of nitrofurantoin in polyethylene glycol are missible in water, forming clear solutions stable for 
at least 48 hours, allowing transmission measurements that were done at $368 \mathrm{~nm}$.
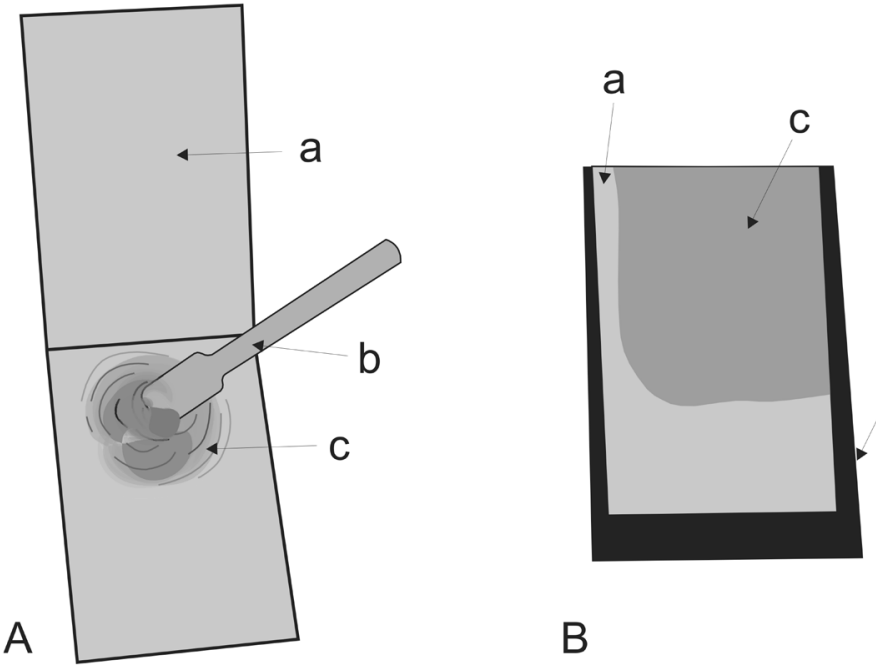

Figure 2. A- Spreading of the nitrofurantoin solution in polyethylene glycol on the rough side of the waxed paper; B- Black foil of PVC (polyvinylchloride) introduced between the two sides of the folded waxed paper. $\mathrm{a}$ - waxed paper (clean); b - laboratory spatula; $\mathrm{c}-$ nitrofurantoin solution in $40 \mathrm{k}$ polyethylene glycol; $\mathrm{d}$ - black foil of PVC (polyvinylchloride).

\section{Analytical curve}

To construct the calibration curve $272.92 \mathrm{mg}$ $\mathrm{g}^{-1}$ of a mixture of nitrofurantoin with starch, talc and lactose $(1: 1: 1 \mathrm{w} / \mathrm{w})$ was used. This mixture was used to prepare a polyethylene glycol nitrofurantoin solution containing $2.1025 \mathrm{mg} \mathrm{g}^{-1}$ of the analyte. This last solution was used to prepare all the aqueous solutions used to construct the analytical curve from ca. $1.6^{\prime} 10^{-3} \mathrm{mg}$ $\mathrm{g}^{-1}$ to ca. $9.0^{\prime} 10^{-3} \mathrm{mg} \mathrm{g}^{-1}$.

The absorbance was measured in the Shimadzu UV-2450 spectrophotometer at $368 \mathrm{~nm}$, using certified $1.00 \mathrm{~cm}$ path length quartz cells.

\section{HPLC method}

The HPLC method recommended by USP [15] was employed. In this procedure acetanilide, $1.00 \mathrm{mg} \mathrm{mL}^{-1}$ in water, is used as internal standard. The mobile phase was a solution containing aqueous phosphate buffer $(\mathrm{pH}=7.0)$ and acetonitrile in the proportion $88: 12 \mathrm{v} / \mathrm{v}$. Nitrofurantoin $(0.04996 \mathrm{~g})$ was dissolved in $40.0 \mathrm{~mL}$ of dimethylformamide. To this solution 50.0 $\mathrm{mL}$ of the internal standard solution was added. This last solution was filtered through a $0.45 \mathrm{~mm}$ porosity nylon filter, rejecting the first milliliters of the filtrate.
The final solution was ready to be injected in the chromatograph, whose detector was adjusted to $254 \mathrm{~nm}$.

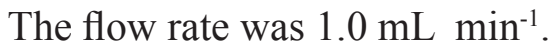

\section{Results and Discussion}

\section{Diffuse reflectance procedure}

From the beginning of this work the aim was to develop a reliable green analytical method that could allow the analysis of nitrofurantoin in the bulk drug and in pharmaceutical preparations with a minimum of manipulation.

As is well known for a reflectance procedure a homogeneous reflecting surface is necessary. In the present case, waxed paper was used with the purpose to homogeneously fix the analyte on its surface. In this case the intensity of light reflected by the analyte was expected to be proportional to its concentration. Nitrofurantoin was dissolved in $40 \mathrm{k}$ polyethylene glycol. The paste formed was applied to the paper with a small laboratory spatula. It is not necessary to weigh this aliquot as the surface and the thickness of the paper delimit the quantity of the analyte.

The solution of the analyte must be applied on the rough side of the paper because the absorption is more effective on this surface.

The commercial form of nitrofurantoin is presented as a solid mixed with starch, talc and lactose, all encapsulated into a brownish material that is not specified by the manufacturer. After crushing, this brown material remains in the powder impeding the direct reflectance measurement of the drug in the solid preparation. Due to this, dissolution in polyethylene glycol was necessary. The brown material is insoluble and remains in suspension whereas nitrofurantoin is easily dissolved. When the waxed paper is soaked with the solution, the non soluble material is automatically separated and remains on the outer surface of the paper, being removed by simply passing a soft tissue such as, for example, a paper handkerchief.

The analytical curve obtained with the Shimadzu UV-2450 spectrophotometer is described by the equation $\mathrm{A}=0.02154+0.06994 \mathrm{C} ;(\mathrm{r}=0.998)$; where $\mathrm{A}$ is the measured absorbance of the light at $385 \mathrm{~nm}$ in the reflection process and $\mathrm{C}$ is the concentration of the drug in $\mathrm{mg} \mathrm{g}^{-1}$ giving LD@0 $0.23 \mathrm{mg} \mathrm{g}^{-1}$ and LQ @ $0.69 \mathrm{mg}$ $\mathrm{g}^{-1}$.

With the portable reflectometer built in our lab- 
oratory [20-22] the following analytical curve was obtained: $r=67.080+47.724 \times C ;(r=0.997)$; where $r$ is the resistance in ohms of the LDR used as sensor in the device and $\mathrm{C}$ is the concentration of the drug in $\mathrm{mg} \mathrm{g}^{-1}$, with LD@0.27 mg g $\mathrm{m}^{-1}$ and LQ@0.81 mg g-1.

Several samples of pharmaceutical preparations obtained in the local market were analyzed. The results are shown in Table 1 where the title "Reflectance I" are those obtained with the Shimadzu spectrophotometer using the diffuse reflectance sphere accessory and the results with the title "Reflectance II" were obtained with the portable reflectometer constructed in our laboratory. These same samples were also used for the transmission and for the HPLC methods.

Table 1. Determination of nitrofurantoin in pharmaceutical preparations by the visible- ultraviolet diffuse reflectance, ultraviolet transmission and HPLC methods.

\section{Transmission procedure}

From a solution of nitrofurantoin in polyethylene glycol containing $2.10 \mathrm{mg} \mathrm{g}^{-1}$ a series of solutions diluted in water, from ca. $1.7 \times 10^{-3} \mathrm{mg} \mathrm{g}^{-1}$ to $1.0 \times 10^{-2} \mathrm{mg}$ $\mathrm{g}^{-1}$ were prepared. The absorbances of these solutions were measured at $368 \mathrm{~nm}$, constituting the analytical curve described by the equation $\mathrm{A}=-0.01228+73.32$ $\mathrm{C}$; $(\mathrm{r}=0.998)$; where A absorbance and $\mathrm{C}$ the concentration of nitrofurantoin in $\mathrm{mg} \mathrm{g}^{-1}$, having LD@0.63 '10 0.3 mg g ${ }^{1}$ and LQ@1.9'1 $10^{3} \mathrm{mg} \mathrm{g}^{1}$. The results are shown in Table 1 with the title "Transmission".

\section{HPLC procedure}

The HPLC procedure was performed according to the USP [15], using acetanilide as internal standard. The results are shown in Table 1 under the title "HPLC".

\begin{tabular}{|c|c|c|c|c|c|c|c|c|c|c|c|c|}
\hline & \multicolumn{3}{|c|}{ Reflectance $I_{\sim}^{\mathrm{a}}$} & \multicolumn{3}{|c|}{ Reflectance $\mathrm{II}^{\mathrm{b}}$} & \multicolumn{3}{|c|}{ Transmission } & \multicolumn{3}{|c|}{ HPLC } \\
\hline Sample & $\underset{/ \mathrm{mg}}{\text { Eound }}$ & $\pm \mathrm{SD}$ & $\underset{\%}{ \pm \mathrm{RSD}}$ & $\frac{\text { Founde }}{/ \mathrm{mg}}$ & $\pm \mathrm{SD}$ & $\underset{\%}{ \pm \text { RSD }}$ & $\begin{array}{l}\text { Founde } \\
/ \mathrm{mg}\end{array}$ & $\pm \mathrm{SD}$ & $\underset{\%}{ \pm \text { RSD }}$ & $\frac{\text { Founde }}{/ \mathrm{mg}}$ & $\pm \mathrm{SD}$ & $\underset{\%}{ \pm \mathrm{RSD}}$ \\
\hline $\mathbf{A}$ & 99 & 4 & 4 & 102 & 10 & 10 & 104 & 3 & 3 & 102 & 2 & 2 \\
\hline B & 100 & 4 & 4 & 97 & 9 & 9 & 108 & 2 & 2 & 104 & 1 & 1 \\
\hline C & 101 & 2 & 2 & 100 & 7 & 7 & 107 & 2 & 2 & 103 & 2 & 2 \\
\hline D & 103 & 3 & 3 & 104 & 8 & 8 & 105 & 2 & 2 & 102 & 2 & 2 \\
\hline $\mathbf{E}$ & 98 & 4 & 4 & 101 & 6 & 6 & 104 & 2 & 2 & 100 & 2 & 2 \\
\hline \multicolumn{3}{|c|}{ Mean RSD \% } & 3.4 & & & 8.0 & & & 2.2 & & & 1.8 \\
\hline
\end{tabular}

${ }^{\mathrm{a}}$ Diffuse reflectance - Shimadzu UV-2450 with accessory; ${ }^{\mathrm{b}}$ diffuse reflectance portable device [17]; ${ }^{c}$ nominal content - $100 \mathrm{mg}$ per capsule.

Table 2. Determination of nitrofurantoin in pharmaceutical preparations. Statistical comparison among the results obtained using the diffuse reflectance, transmission and HPLC methods, using the paired Student's t test and the Snedecor's F test. The degrees of freedom $(\square)$ is 4 as $\square=n 1+n 2-2$ and $n 1=n 2=3$ in the present case; t critical is $2.78(\square=0.05)$ and $4.60(\square=0.01)$; F tabled is $19.0(\square=0.05)$ and $99.0(\square=0.01)\lceil 20\rceil$.

\begin{tabular}{|c|c|c|c|c|c|c|c|c|c|c|c|c|}
\hline & \multicolumn{2}{|c|}{$\begin{array}{l}\text { Reflec } \mathrm{I}^{\mathrm{a}} \\
\text { vs. Reflec } \\
\text { II }^{\mathrm{b}}\end{array}$} & \multicolumn{2}{|c|}{$\begin{array}{l}\text { Reflec Ia } \\
\text { vs. Trans }\end{array}$} & \multicolumn{2}{|c|}{$\begin{array}{c}\text { Reflec II } \\
\text { vs. Trans }\end{array}$} & \multicolumn{2}{|c|}{$\begin{array}{l}\text { Reflec I I } \\
\text { vs. HPLC }\end{array}$} & \multicolumn{2}{|c|}{$\begin{array}{l}\text { Reflec IIb } \\
\text { vs. HPLC }\end{array}$} & \multicolumn{2}{|c|}{$\begin{array}{c}\text { Trans } v s . \\
\text { HPLC }\end{array}$} \\
\hline & $\boldsymbol{t}_{\text {calc }}$ & $F_{\text {castc }}$ & $t_{t} \cos x$ & $F_{\text {Gaic }}$ & catce & $F_{\text {calc }}$ & $t_{\text {calc }}$ & $F_{\text {castc }}$ & $t_{\text {catc }}$ & $F_{\text {castc }}$ & $t_{\text {calc }}$ & $F_{\text {caic }}$ \\
\hline $\mathbf{A}$ & 0.39 & 6.3 & 1.4 & 1.8 & 0.27 & 11.1 & 1.3 & 4.0 & 00 & 25.0 & .78 & 2.3 \\
\hline B & 0.43 & 5.1 & 2.52 & 4.0 & $1.6 \mathrm{~s}$ & 20.3 & 1.3 & 16.0 & 1.0 & 81.0 & 2.53 & 4. \\
\hline C & 0.19 & 12.3 & 2.0 & 1.0 & 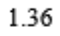 & 12.3 & 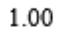 & 1.0 & 0.58 & 12.3 & 2.0 & 1.0 \\
\hline D & 0.17 & 7.1 & 0.7 & 2.3 & 0.17 & 16.0 & 0.7 & 2.3 & 0.34 & 16.0 & 1.50 & 1.0 \\
\hline E & 0.59 & 2.3 & 1.90 & 4.0 & 0.67 & 9.0 & 0.63 & 4.0 & 0.22 & 9.0 & 2.00 & 1.0 \\
\hline
\end{tabular}

${ }^{a}$ Diffuse reflectance - Shimadzu UV-2450 with accessory: ${ }^{\text {b }}$ diffuse reflectance portable equipment [17]. 


\section{Comparison of the methods}

Table 1 shows the results obtained by the three procedures proposed in this work and by the HPLC method. In Table 2 the statistical comparison between all the procedures using the paired Student's t test and the Snedecor's F test [25] is shown.

Observing the values of Table 1, it can be noted that all the analyzed pharmaceutical preparations are in agreement with the declared content of the active principle.

In the statistical comparison between the methods, whose results are shown in Table 2, it can be observed that all procedures offered equivalent results in terms of accuracy at a $95 \%$ confidence level $(a=0.05)$, as the calculated values of $t$ are all below the critical $t$ values. With respect to the precision, statistical equivalence was observed except in two cases (Reflec II vs. HPLC; samples A and B). However at the 99\% confidence level $(\mathrm{a}=0.01)$ complete agreement among the precision of the methods is observed.

Comparing all the methods used from the point of view of laboratory manipulation diffuse reflectance and transmission are doubtless the simplest to be performed and the least expensive. They are also more environmentally friendly as they use only polyethylene glycol and water as solvents in small quantities. In the particular case of the transmission procedure it presents the particular advantage that most common laboratories have at least a small spectrophotometer, which is quite enough for carrying out this analysis.

\section{Conclusion}

It can thus be concluded that the diffuse reflectance and the transmission methods reported in the present article can be proposed for the green quantitative analysis of nitrofurantoin in pharmaceutical preparations and in the bulk drug.

\section{Acknowledgements}

The authors are grateful to $\mathrm{CNPq}$ (Conselho Nacional de Pesquisa Científica e Tecnológica), to FAPESP (Fundação de Amparo à Pesquisa do Estado de São Paulo) for financial support and to Prof. Dr. Carol H. Collins for an English revision of the manuscript.

\section{References}

A. Kleemann, J. Engel, B. Kutschera, D. Reichest, Pharmaceutical Substances: Syntheses, Patentes, Applications, N-Z, fourth ed. Thieme, Berlin, 2001, p 14531454.

W. Tavares, Manual de Antibióticos e Quimioterápicos Antiinfecciosos, Atheneu, São Paulo, 2001.

V. Lorian, Antibiotic in Laboratory Medicine, fifth ed., Lippincott Williams \& Wilkins, Philadelphia, 5rd edn, 2005.

A. Masunari, L. C. Tavares, Rev. Bras. Cienc. Farm., 42(2) (2006) 203.

F. R. Paula, S. H. P. Serrano, L.C. Tavares, Quim. Nova, 32(4) (2009) 1013.

L. L. Bruton, J. S. Lazo, K. L. Parker, in: J. G. Hardam, L.E. Limbird, A.G. Gilman (eds), Goodman \& Gilman: as Bases Farmacológicas da Terapêutica, eleventh ed., McGraw Hill, Rio de Janeiro, 2006.

M. I. Walash. A. M. Elbrashy, M. A. Sultan, Anal. Lett., 26(3) (1993)499.

J. J. B. Nevado, J. R. Flores, M. L. D. Pardo, Analusis, 21(1) (1993) 33.

M. I. Walash, A. M. Elbrashy, M. S. Eldin, M.A., Abuirjeie M. A. E. Sultan, Pharmazie, 49(9) (1994) 698.

M.C. Mahedero, G.T. Díaz, S. G. Pascua, J. Pharm. Biomed Anal., 29 (2002) 477.

T. S. Belal, J. Fluoresc., 18 (2008) 771.

W. Zhang, C. R. Wilson, N.D. Danielson, Talanta, 74 (2008) 1400.

E. Hammam, J. Pharm. Biomed. Anal., 30 (2002) 651.

A. Guzman, L. Agui, M. Pedrero, P. Yanez-Sedeno, J.

M. Pingarron, Eletroanalysis, 16 (21) (2004) 1763.

The United States Pharmacopeia. The National Formulary, twenty fifty ed. Pharmacopeial Convention, Rockville, 2005, p 1380-1383

F. Belal, Chromatographia, 25 (1) (1988) 61.

M. A. Gotardo, R. Sequinel, L. Pezza, H. R. Pezza. Eclet. Quim 33 (4) (2008) 7

M. A. Gotardo, L. Pezza, H.R. Pezza, Eclet. Quím. 30

(2) (2005) 17

M. A. Gotardo, J. O. Tognolli, L. Pezza, H. R. Pezza, Spectrochim. Acta, Part A 69 (4) (2008) 1103

F. A. A. Matias, M. M. D. C. Vila, M. Tubino, Sens. Actuators B Chem., 88 (2003) 60.

F. A. A. Matias, M. M. D. C. Vila, M. Tubino, J. Braz. Chem. Soc., 15 (2004), 327.

M. Tubino, R.L. Souza, Talanta, 68 (2006) 776.

M. Tubino, L. F. Bianchessi, Marta M. D. C. Vila, Anal. Sci. 26 (2010) 121. 
M. Tubino, M.M.D.C. Vila, J.Braz.Chem.Soc. 20 (2009) 1901.

K. Eckschlager, Errors, Measurement and Results in Chemical Analysis, Van Nostrand: Reinhold Company, London, 1972. 